\title{
CINEMATOGRAPHY IN SCIENTIFIC RESEARCH
}

$\mathrm{P}^{\mathrm{T}}$ ROGRESS in scientific research depends on precision instruments, because accurate quantitative data alone can form the ultimate basis of new discoveries. Although infinitely versatile, our human sense organs are very limited when accurate measurements are needed, be they of size, or length or of weight. The invention of the microscope, the micrometer and of the chemical balance have each opened large fields of research, and their accurate measurements have greatly advanced biology, engineering and chemistry. Without such instruments, and the ciné camera is one of them, scientific research would scarcely have progressed beyond the speculative and descriptive stage. To demonstrate the latest results achieved by scientific cinematography, the Scientific and Technical Group of the Royal Photographic Society arranged a special morning session on September 3 at the British Association meeting in Bristol. In spite of many other attractions, it was extremely well attended, and the audience numbered more than three hundred.

The meeting was opened by R. J. Hercock, chairman of the Scientific and Technical Group, who introduced the programme, and by Prof. N. F. Mott, who took the chair during the morning. Prof. Mott was of the opinion that research films are well suited to bring together scientific workers from many different disciplines, and that this is one of the main functions of the British Association. He was followed by Dr. A. R. Michaelis, who had been responsible for the organization of this session. Dr. Michaelis gave a brief outline of the history of the subject, of E. J. Marey's classical contribution and his insistence on the quantitative nature of all scientific cinematography, which he hoped would be stressed by all the other speakers. He mentioned the many cinematographic techniques which have been used in scientific research and gave a few classical examples of their applications in different fields.

The use of high-speed cinematography in physical and engineering research was the subject of $W$. $D$. Chesterman's (Royal Naval Scientific Service) paper and research film. A wide range of problems was shown on the screen, particularly noteworthy being underwater sequences of cavitation phenomena, partly recorded on models in hydrodynamic flow channels and partly recorded in the open sea. Spark cinematography at frequencies up to 100,000 frames/ sec. was demonstrated in ballistic research work and showed in detail the impact of projectiles on armour plating. Mr. Chesterman concluded with a plea for the wider use of underwater cinematography by marine biologists, who might well use this established technique for the study and recording of their subjects in natural surroundings.

An example of the use of high-speed cinematography in industrial research was presented by D.J. Dearnley (Central Research Establishment I, National Coal Board). Froth flotation of fine-coal particles was cinematographically recorded at 2,500 frames/sec. in order to elucidate the mechanism and efficiency of grain attachment to air bubbles. A field-splitting optical system was developed in order to record each bubble simultaneously from two directions at right angles, and from the resulting research film, received with applause at the meeting, it proved possible to measure collection efficiency and contact times as well as to plot the trajectories of particles and bubbles.

The most outstanding research film shown at the meeting was the one dealing with the behaviour of living cells in tissue culture, presented by $\mathrm{E}$. J. Ambrose (Chester Beatty Research Institute, London) and recorded in collaboration with $M$. Abercrombie (University College, London). Combining the new technique of Smith (Baker) interference microscopy with time-lapse einemicrography, Dr. Ambrose was able to show a colour film which left a deep impression on all who saw it and which was received with much applause. The advantage of this new technique was the demonstration of changes in thickness of cells, shown by marked colour changes, and thus providing an extra dimension in the depth of the recorded image. In the film, the behaviour of normal and cancer cells was contrasted, showing that, when two normal cells make contact, adhesions occur on their surfaces which do not take place in the case of tumour cells. Particularly outstanding was the record of the behaviour of cancer cells in the presence of ribonuclease ; this enzyme stimulated the free movements of the cancer cells even further and led to their death through over-digestion of the enzyme.

High-speed cinematography through the microscope, a rare and extremely difficult research technique, was demonstrated with three examples by R. McV. Weston (Simpl, Ltd.). After explaining the technical problems of the technique, Mr. Weston showed its use for recording the movement of mercury in a clinical thermometer, for examining the lever escapement of a watch and for the discharge of elaters and spores from a liverwort. The first two films showed hitherto unknown defects, and the third allowed quantitative evaluation by Prof. C. T. Ingold (Birkbeck College, London), for whom it was taken. In the absence of Dr. J. S. Courtney-Pratt in the United States, Mr. D. P. C. Thackeray (Research Laboratory on the Physics and Chemistry of Surfaces, Cambridge) presented a brief paper and a research film made by the Courtney-Pratt image-sampling technique ; the subject of the film was the explosion of single crystals.

X-ray cinematography, both of the direct and the indirect method, was shown by G. E. H. Foxon (Biology Department, Guy's Hospital Medical School, London) ; the ingenious use of 'Meccano' gears was greatly admired in a film more devoted perhaps to an exposition of technique than of results. J. Underwood (G.K.N. Group Research Laboratory) gave the last paper, describing further examples of the use of high-speed cinematography in industrial research : his first high-speed film showed the passage of liquid in a heat-exchanger model ; his second the initiation of a welding arc under an argon shield by a condenser discharge; and his third, taken at 5,000 frames/sec., allowed the determination of the acceleration characteristics of the blades of a flying shear. Altogether, thirteen films were shown at the meeting, which concluded with excerpts from the American research film, "Color Motion Pictures of the Whole Sky".

Four German research films which had been specially sent over for this meeting were projected 
two days later during the general festival of scientific films. Two of these were "Netzbau der Kreuzspinne" and "Pervitinwirkung bei der Kreuzspinne"; both were made by Prof. H. M. Peters (Zoological Institute, University of Tübingen). The second of these two was particularly noteworthy, as it allowed the quantitative evaluation of the action of benzidrine on the spider Aranea diadema; this was achieved by plotting against time the intervals along the radial threads of the web. "Biologie des Hamsters", Parts 1 and 2, were produced by Dr. I. Eibl-Eibesfeldt (Department of Animal Behaviour, Max-Planck Institute for Marine Biology, Buldern, Westphalia) and showed some remarkable instances of mating behaviour of hamsters as well as of their young. These four films were lent by the Institut für den wissenschaftlichen 'Film, Göttingen, through the courtesy of its director, Dr. G. Wolf.

There can be no doubt that this first collective presentation of research films from many disciplines at a meeting of the British Association was a great success, as the frequent and often lengthy applause by the audience amply demonstrated. The hope can only be reiterated in this article that, at the meeting next year in Sheffield of the British Association, all those who have made research films in the meantime will use the opportunity to present their results ; the films should be submitted to either the Scientific and Technical Group of the Royal Photographic Society or to the Scientific Film Committee of the British Association.

A. R. Mrchaelis

\section{RADIOCARBON DATING CONFERENCE IN CAMBRIDGE}

$\mathrm{T}$ $\mathrm{HE}$ second conference on radiocarbon dating held in Europe took place in Cambridge during the week July 25-30. Dr. H. Godwin, head of the Cambridge dating laboratory at the University Subdepartment of Quaternary Research, Botany School, was the host and inspiring organizer of a most successful and instructive symposium. He assembled a small group of scientists representing almost all the dating stations in Europe, plus a few physicists who are in the process of setting up dating equipment. Thanks to a generous grant from the Wenner-Gren Foundation, New York, it had also been possible to invite a fow of the leading Americans in this field. Thus, the conference was a first step towards the goal set in Copenhagen a year ago, where the estab. lishment of closer personal contact with American colleagues was considered essential for future discussions-in Europe-of the implications of radiocarbon dating.

The Cambridge conference was devoted almost exclusively to the discussion of new methods, which have undergone rapid development in the past two years. The classical Libby method of 'counting' solid carbon in the screen-wall counter is being abandoned, mainly because the widespread contamination of the atmosphere with radioactive dust -although probably too low to be of significance as a health hazard-represents a serious menace to accurate low-level assay. This is particularly true in the case of 'black carbon' samples with their extremely large surfaces and high adsorption capacities.

In the United States and in Europe, a number of new approaches to the measurement of natural radiocarbon have been made simultaneously; for example, gas counting of carbon dioxide, acetylene and methane, and scintillation counting in which the sample to be dated is incorporated into the scintillator. Each of the methods mentioned was discussed in detail at the Cambridge conference, and a comparison of the merits of various techniques was attempted, especially as regards the ease and speed of operation, the accuracy achieved within a given counting time, the relative sample sizes, etc.

Just as at last year's conference in Copenhagen, the question of errors of radiocarbon ages was the subject of lively discussions. In the solid carbon method, the statistical error of the net count represents the largest contribution to the error of the final result. As this error is being suppressed by improving the ratio $S^{2} / B$ (sample over background), other factors such as isotopic fractionation during processing of the samples, variations in the natural isotopic constitution of the unknown and the reference sample, and the uncertainty in the half-life of radiocarbon, etc., begin to play an appreciable part in estimating the accuracy of radiocarbon measurements. Different errors have been combined in a variety of ways, and very few publications contain a concise statement as to how the errors listed have been computed.

A solution of this problem acceptable to all participants could not be found during the Cambridge meeting; but it was agreed that the manner in which the error is calculated should be stated explicitly in future publications.

Moreover, the standardization of the form of publication of dating results was discussed. All investigators present agreed that dating results should be collected at regular intervals for publication in either Nature or Science. They should preferably appear in the form of date lists similar to those issued by Libby, containing only a brief description of the sample, its current laboratory number and the station's identification prefix letter (cf. below). Obviously, publication of date lists will not replace presentation of the same results in their proper context in any other scientific journal ; however, it will make the dating results of various stations more readily accessible to those interested in any one of the widely differing fields of application of the radiocarbon dating method. Also, the results of inter-laboratory cross-checking and standardization, as well as of mass-spectrometric monitoring, are of interest to many workers in this and related fields, and all data should be made available to the widest possible circle of readers. A list of the dating stations in operation or close to completion, and the identification prefix letters used or accepted for use by these stations, is given in Table 1 , and additional information will be appreciated.

\begin{tabular}{llll} 
& \multicolumn{2}{c}{ Table 1. DATING } & IABaratorizs \\
$B M$ & British Museum, London & $P$ & Philadelphia \\
$C$ & Chicago & $Q$ & Cambridge, England \\
$G R O$ & Groningen & $R$ & Rome \\
$G$ & Gothenburg & $G L$ & Royal Institution, London \\
$H$ & Heidelberg & $S$ & Stockholm \\
$K$ & Copenhagen & $T$ & Trondheim \\
$L$ & Lamont (N.Y.) & $W$ & Washington \\
$M$ & Michigan & $Y$ & Yale \\
$?$ & Manitoba & $?$ & New Zealand \\
& & $?$ & Poznan, Poland
\end{tabular}

In this connexion it may be mentioned that an informal exchange of scientific information between European dating laboratories has been in existence for almost two years, and an effort is being made to maintain and widen such contacts among scientists actually engaged in radiocarbon dating. 